\title{
Design de tipos e ensino: uma proposta metodológica
}

Typedesign and education: a methodological proposition

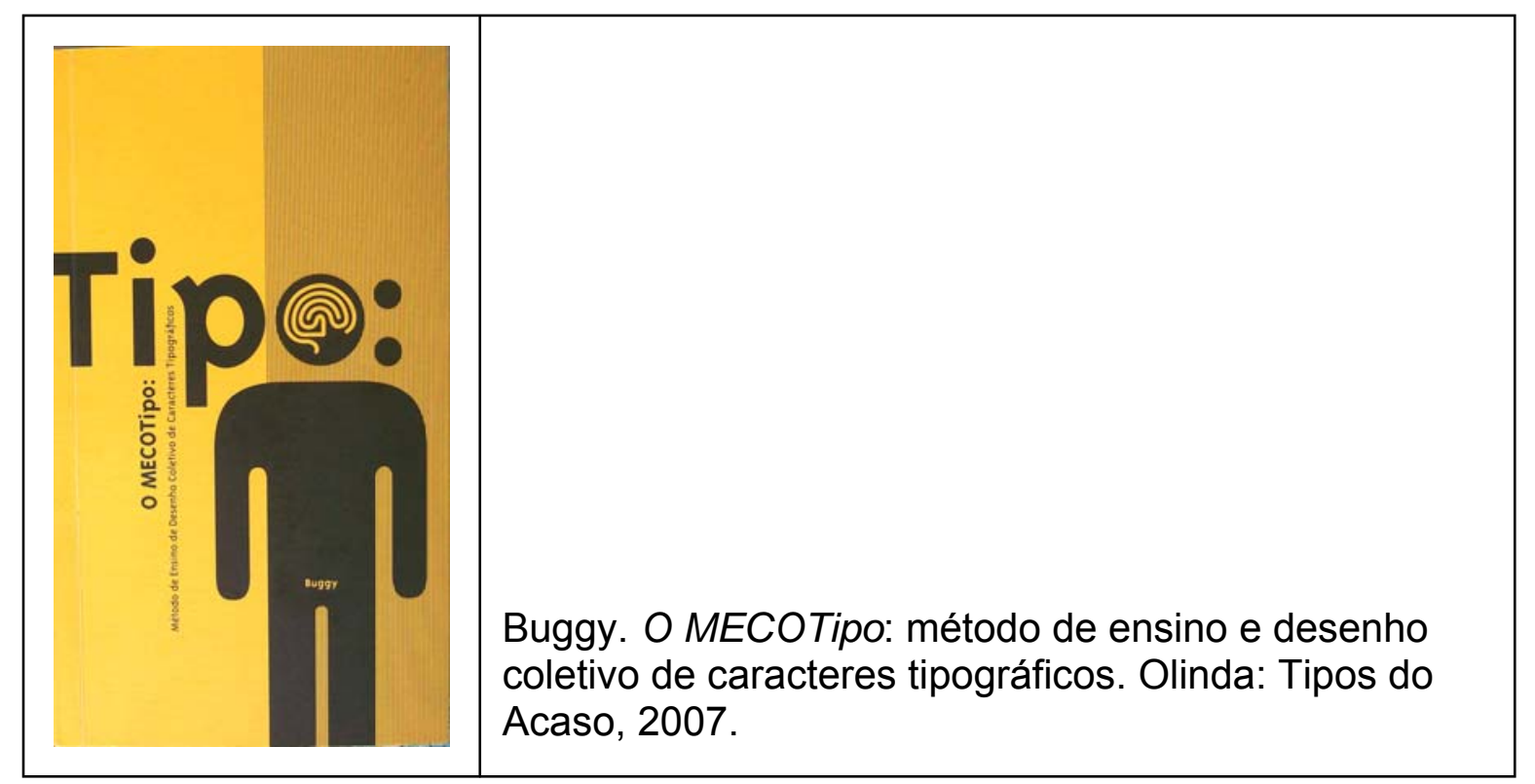

\section{Resumo da obra}

O livro apresenta os resultados de uma pesquisa de mestrado, desenvolvida no Programa de Pósgraduação em Design da UFPE, onde o autor propõe uma metodologia específica para o ensino da disciplina de tipografia em cursos de design gráfico, tendo como objetivo o desenho coletivo de caracteres tipográficos. A proposta baseia-se em um extenso levantamento bibliográfico sobre design de tipos realizado pelo autor, e em suas experiências em sala de aula, como professor de tipografia. A metodologia apresentada consiste, segundo Buggy, em um "método introdutório que propõe um meio de avaliação intimamente ligado a um sistema de exercícios capaz de estimular designers em formação a exercitar o desenho tipográfico através de experimentos" (p.14-15). O livro é dividido em seis capítulos: apresentação do método, parâmetros teórico/metodológicos, parâmetros práticos, programa de aulas e sistema de avaliação. Ao final da obra, o autor apresenta o levantamento bibliográfico sobre tipografia usado na elaboração da pesquisa. O texto é redigido em linguagem técnica, mas de fácil acesso, tendo como públicoalvo estudantes de design.

\section{Summary of the book}

The book presents the results of a master degree research, developed in of the Post-graduate Program in Design at UFPE (Pernambuco Federal University - Brazil). The author proposes a specific methodology for teaching typography in graphic design courses, aiming for the collective design of typefaces. The proposal is based on a bibliographic research about type design made by author, and his experiences in the classroom as a typography teacher. The methodology is presented, according the author, as an "introductory method which proposes means of evaluation linked to a system of exercises capable of stimulating design students to exercise typeface design through experiments" (p. 14-15). The book is divided into six chapters:

presentation of the method, theoretical and methodological parameters, practical parameters, syllabus, and evaluation system. At the end of the book, the author presents the bibliography on typography developed for his research. The text is written in technical language, but in an accessible manner, targeting on design students. 


\section{O método}

A metodologia proposta pelo autor visa despertar nos designers em formação o interesse e a habilidade no desenho de fontes display. Com base em autores consagrados na área de design de tipos, tais como Karen Cheng, Adrian Frutiger, Richard Hendel, Robert Bringhurst, Priscila Farias e Cláudio Rocha, entre outros, o autor desenvolve um método próprio, composto por parâmetros que incluem a apresentação do conteúdo teórico, os exercícios práticos, um programa de aulas e um sistema de avaliação de resultados dos experimentos. Cada um dos parâmetros, tanto os práticos como os teóricos, foi dividido em quatro postulados. Segundo o autor, a pesquisa teve início com estudos de textos de Emil Ruder sobre os aspectos geométricos, ópticos e orgânicos na percepção da relação figura e fundo das imagens.

\section{Os parâmetros teórico/metodológicos}

Buggy apresenta cada um dos parâmetros com sua divisão em quatro postulados, de modo a facilitar a compreensão do método e o acompanhamento dos resultados.

O primeiro postulado determina o tempo de duração da disciplina. $O$ autor prevê uma faixa de tolerância em função de possíveis alterações de carga horária, e define que o método necessita de uma carga horária mínima de $48 \mathrm{~h}$ e máxima (ideal) de $60 \mathrm{~h}$. Segundo o autor, essa carga horária é aquela normalmente disponível para as disciplinas de tipografia em cursos de design nas instituições brasileiras de ensino superior.

O segundo postulado determina a consulta à bibliografia disponibilizada pelo professor, tendo em vista que os alunos adquiram, através desta, conhecimentos técnicos e teóricos necessários para a realização dos experimentos. Assim como no terceiro postulado, que regula a auto-avaliação do professor, o conteúdo teórico apresentado pelo segundo postulado baseia-se, segundo o autor, em material coletado pela fundidora Tipos do Acaso. A auto-avaliação do professor determina que ele realize todos os experimentos do método, de modo a familiarizar-se com os exercícios e compreender os níveis de complexidade de cada experimento.

No quarto postulado o autor determina a necessidade de avaliação do desempenho dos alunos, orientada pelos objetivos específicos de cada experimento.

\section{Os parâmetros práticos}

Os parâmetros práticos também se dividem em quatro postulados hierarquizados, de modo que cada aluno possa acompanhar seu próprio desenvolvimento. No primeiro postulado o autor propõe um experimento surpresa em que os alunos são submetidos a um primeiro contato com o desenho de um caractere. No segundo postulado, os alunos são submetidos ao desenho de 62 caracteres sobre uma malha de construção.

Posteriormente, os alunos desenham um alfabeto completo a partir dos caracteres-chave $\mathrm{n}, \mathrm{o}, \mathrm{Ne}$ $\mathrm{O}$, de acordo com o tema definido por um grupo. O tema é escolhido com base nas possibilidades que ele tem de influenciar nas características do desenho tipográfico. Cada grupo deve apresentar um tema, um recorte do tema, um texto descritivo, os tópicos do conteúdo semântico ${ }^{1}$ e os atributos de correlação que serão usados no desenho dos caracteres.

O quarto postulado deste parâmetro tem por objetivo o desenho coletivo de cem caracteres a partir de novos grupos e de novos temas.

Observa-se que a seqüência de exercícios estabelece uma ordem progressiva, na qual os alunos são levados ao desenvolvimento e aperfeiçoamento dos desenhos.

Baseado nos arquétipos de derivação o, h, p e v, propostos por Anne Debra Adams (1989), Buggy propõe seus próprios arquétipos, tanto para a caixa-baixa quanto para a caixa-alta, nos caracteres $n, o, N$, O. A partir deles os alunos devem dar continuidade ao alfabeto com o desenho dos caracteres $p, h, a, e, c$, j, v, e k, que, segundo o autor, "fornecem atributos de correlação de desenho, também associados ao conteúdo semântico" (p.29). O desenho dos sinais, a pontuação, acentos e caracteres para-alfabéticos são realizados a partir da observação em fontes já publicadas.

\section{O programa de aulas}

O autor salienta a importância de variações no programa de aulas, em função do tempo em sala. As variações podem se dar na quantidade de encontros e no desempenho dos alunos no decorrer da

\footnotetext{
${ }^{1}$ O autor usa a expressão "conteúdo semântico do projeto tipográfico" para se referir ao conceito adotado pelos alunos participantes da proposta de ensino, visando o desenvolvimento de fontes display.
} 


\section{Infodesıgn}

disciplina. Com isso o autor considera, para o MECOTipo, um número de vinte participantes com tolerância mínima de dez e máxima de 25 , excluindo professores e possíveis monitores.

O programa é dividido em nove partes consecutivas, e a carga horária ideal é determinada em 15 aulas de 4 horas cada.

As aulas expositivas enfatizam a apresentação de termos e definições (tipografia ou tipologia, fonte ou tipo etc.), classificação de famílias, seleção e combinação de fontes em projetos gráficos, proporções do tipo, efeitos ópticos, conselhos para o desenho de fontes, espacejamento e kerning.

\section{O sistema de avaliação}

Buggy propõe um sistema de avaliação específico para o desenho de fontes display. Cada um dos experimentos é avaliado e pontuado de acordo com objetivos específicos. $O$ autor defende a necessidade de uma avaliação processual, que não se resuma a um momento de aplicação de prova escrita ou oral com resultados numéricos, mas que consiga diagnosticar o desempenho de cada aluno ao longo de toda a disciplina.

\section{A contribuição}

No livro, a discussão sobre o tema tem, especificamente, duas abordagens: a do designer de tipos, presente em todo o conteúdo técnico do livro, inclusive na terminologia da área, e a do educador em tipografia, entendida como o foco principal do método apresentado.

Embora a abordagem se dê sob a ótica da proposição de um método pedagógico para o design, o autor, em momento algum, discute, ou apresenta, referências claras a respeito de pedagogia ou didática. A bibliografia especificada ao final do livro aponta referências da área de educação - autores como Coutinho (1998), Freinet (1977), Morin (2001) e o próprio Ministério da Educação. Ao longo do livro, contudo, encontram-se citações diretas apenas a autores da área de design de tipos. O leitor interessado em pedagogia do design, ou mesmo interessado na aplicação do método em programas de ensino, certamente se beneficiaria pela inclusão de reflexões mais aprofundadas sobre essas referências.

De forma mais ampla, e voltada à prática profissional, Bringhurst (2005) descreve detalhadamente, em seu livro Elementos do estilo tipográfico, procedimentos recomendados ao uso da tipografia em projetos de design gráfico. Diferente de Buggy, Bringhurst compreende a tipografia a partir de uma abordagem histórica, disciplinando e intensificando a prática tipográfica como ferramenta para se solucionar problemas de linguagem e composição de textos. A importância de um apanhado sólido sobre a história da tipografia em qualquer método de ensino dessa prática chama a atenção para uma proposta interdisciplinar. Segundo Cardoso, "A história do design deriva de várias vertentes metodológicas. Baseia-se, principalmente, na história social, voltada para a produção, circulação e recepção de bens de consumo." (2005:15). Todas essas áreas, em conjunto, determinam um sistema de trabalho que é característico das atividades de design. Essa consideração deve refletir diretamente nos métodos de ensino dos cursos de graduação visando à formação de um olhar sociocultural no designer sobre sua atividade prática. Barbosa (2006:3), afirma que

\footnotetext{
Uma pesquisa de car áter interdisciplinar exige uma incursão não apenas no q ue seria o objetivo fin al da pes quisa $\mathrm{p}$ ara um pr ojeto, ou sej a, se u resulta do fi nal $n$ a forma de produto, mas obriga o pesquisador/designer a pass ar necessariamente por outras áreas do con hecimento, debatendo-as e formand o juízos, mesmo que pr ovisórios, sobre es sas outras áreas, a fim de relacioná-las em sua pesquisa e em seu projeto.
}

No MECOTipo, Buggy não reflete essas questões interdisciplinares como componente indispensável ao método de ensino tipográfico, embora apresente uma estrutura aprofundada no que tange a uma proposta de ensino para o desenho de tipos. Lupton (2005), em seu livro Pensar com tipos, aponta procedimentos práticos de diagramação e composição tipográfica. De forma didática a autora relaciona 0 uso dos tipos em projetos editoriais, levantando questões pontuais sobre classificação tipográfica e possibilidades de aplicação. Em contrapartida ao trabalho de Buggy, que se destina a um público estudantil e de acadêmicos que lecionam a disciplina de tipografia, Lupton focaliza uma esfera mais abrangente, disponibilizando conselhos e reflexões pertinentes à prática dos designers gráficos em geral.

Cabe salientar que a proposta de Buggy é motivada por uma pesquisa acadêmica, que requer precisamente um tempo determinado de execução e reflexão de fatores que interferem no tema. Com isso, 
espera-se que o autor apresente certas limitações, mesmo que sem interferências profundas nos objetivos delimitados inicialmente.

A contribuição de Buggy para a prática do design de tipos no Brasil é clara. O desenvolvimento de uma metodologia apropriada, tanto ao desenvolvimento de fontes digitais quanto à prática de ensino da disciplina de tipografia nas escolas de design gráfico, merece distinto respeito. Especialmente por se tratar de uma produção brasileira, numa fase de grande efervescência do design de caracteres e símbolos digitais, o livro termina por se configurar como obra de referência no campo. Os textos apresentados ao final do livro, incluindo técnicas de espacejamento, ajustes de hint e kern, técnicas importantes ao projeto tipográfico, são pontos fortes na obra. display.

O interessado tem às mãos uma fonte de referência para o ensino e a prática do design de fontes

\section{Referências bibliográficas}

BARBOSA, Carlos Alberto. (2006). Tipografia e interdisciplinaridade. In: CONGRESSO BRASILEIRO DE PESQUISA E DESENVOLVIMENTO EM DESIGN, 7. Anais... Paraná. Disponível em www.design.ufpr.br/ped2006/home.htm. Acesso em: 12 nov. 2004.

BRINGHURST, Robert. (2005). Elementos do estilo tipográfico. São Paulo: Cosac Naify.

CARDOSO, Rafael. (2005). O design brasileiro antes do design: aspectos da história gráfica. São Paulo: Cosac Naify.

LUPTON, Ellen. (2006). Pensar com tipos: guia para designers, escritores, editores e estudantes. São Paulo: Cosac Naify.

\section{Sobre o autor}

Fabio Mariano é designer habilitado em comunicação visual pela Unifacs (2007), tendo sido membro pesquisador do grupo A Casa do Tipo, em Salvador. Atualmente é designer gráfico da Fonte Design, em São Paulo, e desenvolve pesquisa com o tema "Variações Tipográficas" no Grupo de Pesquisa em Tipografia e Linguagem Gráfica do Centro Universitário Senac, onde é aluno do programa de mestrado em design. 